\title{
CÁTIONS HIDROSSOLÚVEIS NA PARTE AÉREA DE CULTURAS ANUAIS MEDIANTE APLICAÇÃO DE CALCÁRIO E GESSO EM SUPERFÍCIE ${ }^{(1)}$
}

\author{
Rogério Peres Soratto ${ }^{(2)} \&$ Carlos Alexandre Costa Crusciol ${ }^{(3)}$
}

\begin{abstract}
RESUMO
A eficiência da calagem superficial pode ser melhorada por meio de compostos orgânicos hidrossolúveis liberados por resíduos vegetais. No entanto, não se sabe se os teores desses compostos nos resíduos das culturas podem ser modificados pela aplicação de calcário e gesso em superfície. O presente trabalho objetivou avaliar os efeitos das aplicações de calcário e gesso em superfície sobre os teores de cátions solúveis nos resíduos vegetais das culturas de arroz, feijão e aveia-preta. O experimento foi realizado em um Latossolo Vermelho distroférrico de Botucatu (SP). O delineamento foi de blocos casualizados com parcelas subdivididas e quatro repetições. As parcelas foram constituídas por quatro doses de calcário dolomítico $\left(0,1.100,2.700\right.$ e $\left.4.300 \mathrm{~kg} \mathrm{ha}^{-1}\right)$ e as subparcelas, pela aplicação ou não de $2.100 \mathrm{~kg} \mathrm{ha}^{-1}$ de gesso agrícola. Para as culturas de verão foi utilizado esquema de parcela subsubdividida. As subsubparcelas foram constituídas por dois cultivares de arroz de terras altas (Caiapó e IAC 202), no ano agrícola 2002/03, e dois cultivares de feijão (Pérola e Carioca), em 2003/04. A aveia-preta foi cultivada no inverno dos dois anos, utilizando apenas o cultivar Comum. Os teores de cátions solúveis na parte aérea das culturas de arroz, feijão e aveia-preta foram alterados pela aplicação de calcário e gesso em superfície. A gessagem em superfície aumentou os teores solúveis de Ca e reduziu o de Mg na parte aérea das culturas, principalmente nas primeiras safras após a aplicação. A calagem aumentou os teores de cátions solúveis na parte aérea de todas as culturas. As culturas do feijão e da aveia-preta apresentaram maiores teores de cátions solúveis nos resíduos da parte aérea, avaliados no florescimento.
\end{abstract}

Termos para indexação: resíduo vegetal, acidez do solo, calagem, gessagem, plantio direto.

\footnotetext{
(1) Parte da Tese de Doutorado do primeiro autor apresentada à Faculdade de Ciências Agronômicas, Universidade Estadual Paulista - FCA/UNESP. Recebido para publicação em fevereiro de 2006 e aprovado em dezembro de 2006.

(2) Professor Assistente do Departamento de Produção Vegetal da Faculdade de Ciências Agronômicas, Universidade Estadual Paulista - FCA/UNESP. Campus de Botucatu, Caixa Postal 237, CEP 18603-970 Botucatu (SP). E-mail: soratto@fca.unesp.br

(3) Professor Adjunto do Departamento de Produção Vegetal, FCA/UNESP. Bolsista do CNPq. E-mail: crusciol@fca.unesp.br
} 


\title{
SUMMARY: WATER-SOLUBLE CATIONS IN SHOOTS OF ANNUAL CROPS AS AFFECTED BY LIME AND PHOSPHOGYPSUM SURFACE APPLICATION
}

\begin{abstract}
Surface liming efficiency can be increased through water-soluble organic compounds released by plant residues. However, it is unknown if the contents of these compounds in crop residues can be modified by lime and phosphogypsum surface applications. The objective of this study was to evaluate effects of lime and phosphogypsum surface applications on the content of water-soluble cations in crop residues of rice, common bean and black oat. The experiment was carried out on a Haplorthox located in Botucatu County, São Paulo State, Brazil. A randomized complete block design, in a split-plot scheme and four replications was used. The plots consisted of four dolomitic limestone levels $(0 ; 1,100$; 2,700; and 4,300 $\left.\mathrm{kg} \mathrm{ha}^{-1}\right)$. The subplots were represented by the presence or absence of phosphogypsum application $\left(2,100 \mathrm{~kg} \mathrm{ha}^{-1}\right)$. For the summer crops a split-split-plot scheme was used. The subsubplots were constituted by two upland rice cultivars (Caiapó and IAC 202), in the growing season of 2002/03, and two common bean cultivars (Carioca and Pérola), in the 2003/2004 growing season. In the winter season of 2003 and 2004, black oat was grown on the entire area, using only one cultivar. The water-soluble cation content in rice shoots, common bean and black oat crops were affected by lime and phosphogypsum surface applications. Surface application of phosphogypsum increased Ca and decreased $\mathrm{Mg}$ water-soluble contents in crop shoots, mainly in the first years of cultivation. Surface liming increased the water-soluble cation contents in all crop shoots. The highest watersoluble cation contents in shoot residues were measured in common bean and black oat during flowering.
\end{abstract}

Index terms: plant residue, soil acidity, liming, phosphogypsum application, no-tillage.

\section{INTRODUÇÃO}

Estudos têm demonstrado o efeito de resíduos vegetais sobre a mobilidade de cátions no solo (Franchini et al., 1999a,b; Meda et al., 2001; Franchini et al., 2001, 2003; Miyazawa et al., 2002). Segundo Caires (2000) e Miyazawa et al. (2000), a permanência de resíduos vegetais na superfície e a ausência de revolvimento do solo reduzem a taxa de decomposição dos ligantes orgânicos por microrganismos; com a disponibilidade de água, os compostos orgânicos podem ser solubilizados e lixiviados. Esse fato, somado ao constante aporte de resíduos, possibilita a produção contínua desses compostos orgânicos, podendo resultar em sua perenização no solo (Amaral et al., 2004). Franchini et al. (2001, 2003) observaram que a capacidade dos resíduos vegetais em mobilizar cátions em solos ácidos está relacionada com o teor de ácidos orgânicos de baixo peso molecular, como: cítrico, málico e t-aconítico.

Na planta, esses compostos estão na forma de ânions orgânicos para manutenção da eletroneutralidade química, devido à absorção de cátions básicos (Pierre \& Banwart, 1973); além disso, apesar da existência de ânions inorgânicos $\left(\mathrm{NO}_{3}^{-}, \mathrm{SO}_{4}^{2-}, \mathrm{H}_{2} \mathrm{PO}_{4}^{-} \mathrm{e} \mathrm{Cl}-\right.$ ) no tecido vegetal, estes apresentam-se em teores pouco significativos. Assim, como a determinação de cátions no tecido vegetal é relativamente mais fácil do que a de ânions orgânicos, a somatória de cátions é um dos melhores indicadores dos efeitos de resíduos na química da solução de solos ácidos (Franchini et al., 1999a; Meda et al., 2001; Cassiolato et al., 2000, 2002; Miyazawa et al., 2002). Dessa forma, a determinação da soma de cátions solúveis pode indicar o potencial de mobilização de cátions e as quantidades de $\mathrm{H}^{+} \mathrm{e}$ $\mathrm{Al}^{3+}$ que podem ser neutralizadas pelos resíduos vegetais, correlacionando-se com os efeitos dos materiais vegetais no aumento do $\mathrm{pH}$ e do Ca trocável e na diminuição do $\mathrm{Al}$ trocável do solo (Franchini et al., 1999a; Miyazawa et al., 1993; Meda et al., 2001; Cassiolato et al., 2002), pois os cátions $\mathrm{Ca}, \mathrm{Mg}, \mathrm{K}, \mathrm{Na}$ e Mn ligados nos compostos orgânicos são substituídos por $\mathrm{H}^{+}$ou $\mathrm{Al}^{3+}$, formando compostos estáveis protonados ou complexo Al - orgânico (Miyazawa et al., 2000).

A quantidade de ácidos orgânicos no tecido vegetal está diretamente relacionada com a atividade metabólica e, conseqüentemente, com seu estádio de desenvolvimento, o que os torna mais abundantes nos resíduos manejados em seu pleno crescimento vegetativo ou início do florescimento, situação comum em plantas de cobertura (Franchini et al., 2003). Ademais, observou-se que o efeito do resíduo vegetal sobre a mobilidade do calcário no solo varia com a espécie e com os cultivares da uma mesma espécie (Cassiolato et al., 2000; Miyazawa et al., 2002).

Como a calagem e a gessagem influenciam a disponibilidade de nutrientes no solo e a absorção destes pelas plantas, também podem influenciar o teor desses nutrientes que se apresenta na forma solúvel na planta. Nesse sentido, o objetivo do presente 
trabalho foi avaliar os efeitos das aplicações em superfície de calcário e gesso no teor de cátions solúveis nos resíduos vegetais das culturas de arroz, feijão e aveia-preta, na época do florescimento.

\section{MATERIAL E MÉTODOS}

O trabalho foi realizado no período de outubro de 2002 a setembro de 2004, na Fazenda Experimental Lageado, pertencente à Faculdade de Ciências Agronômicas - UNESP, município de Botucatu, SP, localizada a $48^{\circ} 23^{\prime} \mathrm{W}$ e $22^{\circ} 51^{\prime} \mathrm{S}$, com altitude de $765 \mathrm{~m}$. O solo do local é um Latossolo Vermelho distroférrico (Embrapa, 1999). O clima, conforme a classificação de Köppen, é do tipo Cwa, que se caracteriza como tropical de altitude, com inverno seco e verão quente e chuvoso.

Em agosto de 2002, amostrou-se o solo, na profundidade de 0-0,20 m, para determinação das características químicas, realizada de acordo com Raij et al. (2001), cujos resultados foram: matéria orgânica de 20,9 $\mathrm{g} \mathrm{dm}^{-3} ; \mathrm{pH}\left(\mathrm{CaCl}_{2}\right)$ de 4,2; $\mathrm{P}$ (resina) de 9,2 $\mathrm{mg} \mathrm{dm}^{-3} ; \mathrm{K}, \mathrm{Ca}, \mathrm{Mg}$ e CTC de 1,2, 14,0, 5,0 e $58,0 \mathrm{mmol}_{\mathrm{c}} \mathrm{dm}^{-3}$, respectivamente; e V \% $=37 \%$. Os teores de areia, silte e argila foram, respectivamente, de 545, 108 e $347 \mathrm{~g} \mathrm{~kg}^{-1}$, na camada de 0-0,20 m, e 513,127 e $360 \mathrm{~g} \mathrm{~kg}^{-1}$ na camada de 0,20-0,40 m de profundidade.

O delineamento experimental utilizado foi em blocos casualizados em esquema de parcelas subdivididas, com quatro repetições. As parcelas (5,4 x 18,0 m) foram constituídas por quatro doses de calcário dolomítico $\left(0,1.100,2.700\right.$ e $\left.4.300 \mathrm{~kg} \mathrm{ha}^{-1}\right)$, que apresentava 23,3\% de $\mathrm{CaO}, 17,5 \%$ de $\mathrm{MgO}$ e $71 \%$ de PRNT, visando elevar a saturação por bases para 50, 70 e $90 \%$, respectivamente. As subparcelas foram constituídas pela ausência ou presença da aplicação de $2.100 \mathrm{~kg} \mathrm{ha}^{-1}$ de gesso agrícola (6 x teor de argila em $\mathrm{g} \mathrm{kg}^{-1}$, na camada de $0,20-0,40 \mathrm{~m}$ de profundidade), sendo esse produto resíduo da indústria de fertilizantes fosfatados. Cada subparcela tinha a dimensão de 48,6 $\mathrm{m}^{2}$ (5,4 x 9,0 m). Foram mantidas distâncias de 8,0 m entre as parcelas dentro de cada bloco e de 3,0 m entre os blocos. Para as culturas de verão foi utilizado o esquema de parcelas subsubdivididas, sendo as subsubparcelas constituídas por dois cultivares de arroz de terras altas (Caiapó e IAC 202) no ano agrícola 2002/2003 e dois de feijão (Pérola e Carioca) no ano agrícola 2003/2004.

A calagem foi realizada sobre os restos culturais de guandu, que foi cultivado em toda a área em 2001/2002, no dia $15 / 10 / 2002$, nas parcelas onde estava previsto esse tratamento. No dia 16/10/2002 realizou-se a aplicação de gesso agrícola em metade de todas as parcelas. Tanto o calcário quanto o gesso foram aplicados superficialmente, sem incorporação mecânica no solo.
Os cultivares de arroz e feijão foram semeados em 20/11/2002 e 6/1/2004, respectivamente, em sistema plantio direto. Na cultura do arroz foram utilizadas 70 sementes por metro linear, num espaçamento entre linhas de 0,30 m. Cada subsubparcela foi constituída por oito linhas de $9 \mathrm{~m}$ de comprimento, localizadas na faixa central de cada subsubparcela, que apresentava 2,7 m de largura. No cultivo do feijão, utilizaram-se 18 sementes por metro linear, num espaçamento entre linhas de 0,45 m, sendo cada subparcela constituída por cinco linhas de $9 \mathrm{~m}$ de comprimento, também localizadas na faixa central de cada subsubparcela, ou seja, não foi cultivado $0,225 \mathrm{~m}$ em cada lateral, devido à configuração da semeadora mecânica. A população final de plantas obtida na cultura do feijão foi de 294.000 plantas ha ${ }^{-1}$. A adubação básica, em ambos os cultivos, constituiu-se de $300 \mathrm{~kg} \mathrm{ha}^{-1} \mathrm{da}$ fórmula-NPK 08-28-16 + 4,5\% de S + 0,5 \% de Zn.

Após a colheita das culturas de verão, nos dois anos agrícolas, foi semeada aveia-preta (Avena strigosa Schreber), cultivar Comum, em 30/4/2003 e 26/4/2004, respectivamente, em toda a área experimental, num espaçamento entre linhas de 0,17 m. Cada subparcela foi constituída por 26 linhas de $9 \mathrm{~m}$ de comprimento, ou seja, não foi semeado $0,49 \mathrm{~m}$ nas laterais de cada subparcela. A adubação básica constituiu-se de $200 \mathrm{~kg} \mathrm{ha}^{-1}$ da fórmula NPK 10-20-10 no primeiro ano e 04-20-10 + 7,0 \% de S no segundo ano.

Foram realizadas adubações de cobertura apenas nas culturas de verão, com a aplicação de $50 \mathrm{~kg} \mathrm{ha}^{-1}$ de $\mathrm{N}$ na forma de uréia, aos 45 dias após a emergência das plantas de arroz. Na cultura do feijão, quando as plantas se encontravam nos estádios $V_{4}$ e $R_{5}$, aplicaram-se 70 e $40 \mathrm{~kg} \mathrm{ha}^{-1}$ de $\mathrm{N}$, respectivamente, na forma de nitrato de amônio.

No florescimento de cada cultura, realizou-se a coleta da parte aérea das plantas contidas em $2 \mathrm{~m}$ de fileira, em cada subsubparcela, no caso da cultura do arroz (2002/2003), e em cada subparcela, no caso da cultura da aveia-preta (nos dois anos agrícolas). Na cultura do feijão realizou-se a coleta de 10 plantas por subsubparcela. As plantas foram cortadas rente ao solo e acondicionadas em sacos de papel devidamente identificados, os quais foram levados para secagem em estufa de ventilação forçada à temperatura de $65^{\circ} \mathrm{C}$, até atingirem peso constante. Em seguida, as plantas foram moídas, passadas em peneira de 1,0 mm e armazenadas em sacos plásticos, para posterior avaliação da qualidade do resíduo vegetal, segundo método descrito por Miyazawa et al. (2000) e Meda et al. (2002).

Para extração dos compostos hidrossolúveis (ácidos orgânicos de baixo peso molecular), transferiu-se $1 \mathrm{~g}$ dos resíduos para frascos de $100 \mathrm{~mL}$ e foram adicionados $50 \mathrm{~mL}$ de água destilada, agitando-se por quatro horas, com posterior filtragem em papel-filtro qualitativo de filtragem rápida.

De posse dos extratos vegetais, os teores de $\mathrm{Ca}$, $\mathrm{Mg}, \mathrm{K}$ e Mn foram determinados por espectrometria 
de emissão ótica com plasma acoplado indutivamente (ICP-OES). Os resultados foram expressos em $\mathrm{mmol}_{\mathrm{c}} \mathrm{kg}^{-1}$, de forma individual para cada elemento e na forma de soma de cátions ( $\Sigma \mathrm{Ca}, \mathrm{Mg}, \mathrm{K}$ e Mn). A soma de cátions solúveis constitui as quantidades de $\mathrm{H}^{+}$e $\mathrm{Al}^{3+}$ que podem ser neutralizadas pelo resíduo vegetal (Miyazawa et al., 2000).

Foi também determinada, no extrato vegetal, a condutividade elétrica (CE) da solução por condutivimetria, em $\mu \mathrm{S} \mathrm{cm} \mathrm{cm}^{-1}$, de acordo com a proposta de Miyazawa et al. (2000).

Os resultados foram submetidos à análise de variância. As médias referentes à aplicação de gesso e cultivares (arroz e feijão) foram comparadas pelo teste t(DMS) a $5 \%$, enquanto os efeitos das doses de calcário foram avaliados por meio de análise de regressão, adotando-se como critério para escolha do modelo a magnitude dos coeficientes de regressão a $5 \%$ pelo teste t.

\section{RESULTADOS E DISCUSSÃO}

Para a cultura do arroz, no primeiro ano do experimento, verificou-se que a aplicação de gesso proporcionou elevação nos teores de Ca e Mn solúveis (Quadro 1). O maior teor de Ca solúvel pode ser explicado pelo fato de o gesso ser fonte deste nutriente. Os efeitos do gesso no aumento do teor de Mn solúvel no resíduo da cultura do arroz podem estar associados ao aumento nos teores de sulfato no solo, pois pode ter havido formação de par iônico entre o $\mathrm{Mn}^{2+}$ e o $\mathrm{SO}_{4}{ }^{2-}$ $\left(\mathrm{MnSO}_{4}{ }^{0}\right)$, diminuindo a atividade desse cátion livre $\left(\mathrm{Mn}^{2+}\right)$ em solução, favorecendo, assim, o deslocamento do equilíbrio no solo, liberando mais íons Mn para a solução e permitindo maior absorção pelas plantas (Olsen \& Watanabe, 1979).

Apesar de ter aumentado os teores de Ca e Mn solúveis nos extratos dos resíduos da cultura do arroz, a aplicação de gesso não alterou de forma significativa a soma de cátions nem a condutividade elétrica da solução, provavelmente porque o $\mathrm{Ca}$ e o $\mathrm{Mn}$ se apresentaram em pequenos teores na forma solúvel, nas plantas de arroz, por ocasião do florescimento (Quadro 1). Meda et al. (2001) verificaram baixo teor de Ca solúvel em resíduos de arroz coletados após a colheita dos grãos.

Houve diferença entre os cultivares de arroz quanto ao teor de $\mathrm{K}$ e Mn dissolvidos nos extratos (Quadro 1). $\mathrm{O}$ cultivar Caiapó apresentou maior teor de $\mathrm{K}$ e menor teor de Mn solúvel. Provavelmente, por apresentar maior teor de $\mathrm{K}$ solúvel, o extrato dos resíduos do cultivar Caiapó também apresentou maior condutividade elétrica, podendo ter maior efeito na mobilidade do calcário aplicado em superfície (Franchini et al., 1999a; Cassiloato et al., 2002; Miyazawa et al., 2002). Os resultados corroboram os obtidos por Cassiolato et al. (2000), os quais observaram diferença entre cultivares de uma mesma espécie (aveia-preta e aveia-branca) quanto à capacidade de aumentar a eficiência da calagem superficial.

A calagem proporcionou aumento nos teores de $\mathrm{K}$ e Mn solúveis, independentemente da aplicação de gesso, e nos teores de $\mathrm{Mg}$ e na soma de cátions, nos extratos vegetais, quando aplicada na presença de gesso (Figura 1). A calagem pode aumentar a disponibilidade de $\mathrm{K}$ no solo quando o efeito de deslocamento do $\mathrm{K}^{+}$do complexo de troca para a solução do solo for superior ao efeito competitivo nos processos de absorção, decorrente das maiores concentrações de $\mathrm{Ca}^{2+} \mathrm{e} \mathrm{Mg}^{2+}$ na solução do solo.

Quadro 1. Teores de cátions solúveis nos resíduos vegetais de cultivares de arroz na época do florescimento e condutividade elétrica do extrato, considerando a aplicação superficial de gesso

\begin{tabular}{|c|c|c|c|c|c|c|}
\hline \multirow{2}{*}{ Tratamento } & \multicolumn{5}{|c|}{ Cátion solúvel } & \multirow{2}{*}{ Condutividade elétrica } \\
\hline & $\mathrm{Ca}^{2+}$ & $\mathrm{Mg}^{2+}$ & $\mathbf{K}^{+}$ & $\mathbf{M n}^{2+}$ & $\Sigma^{(1)}$ & \\
\hline Gesso & & 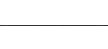 & $\mathrm{mol}_{\mathrm{c}} \mathrm{kg}$ & & - & $\mu \mathrm{S} \mathrm{cm}{ }^{-1}$ \\
\hline Sem & $6,0 \mathrm{~b}$ & 177,7 & 334,3 & $6,8 \mathrm{~b}$ & 524,8 & 1.186 \\
\hline Com & $7,2 \mathrm{a}$ & 188,4 & 333,4 & 8,5 a & 537,5 & 1.187 \\
\hline \multicolumn{7}{|l|}{ Cultivar } \\
\hline Caiapó & 6,5 & 178,6 & 348,6 a & $5,8 \mathrm{~b}$ & 539,5 & $1.238 \mathrm{a}$ \\
\hline IAC 202 & 6,7 & 187,4 & $319,1 \mathrm{~b}$ & 9,5 a & 522,7 & $1.136 \mathrm{~b}$ \\
\hline Média & 6,6 & 183,0 & 333,8 & 7,7 & 531,1 & 1.187 \\
\hline $\mathrm{CV}_{1}(\%)$ & 35,9 & 19,8 & 10,5 & 26,1 & 11,5 & 9,8 \\
\hline $\mathrm{CV}_{2}(\%)$ & 26,6 & 20,4 & 8,9 & 23,9 & 5,8 & 8,0 \\
\hline $\mathrm{CV}_{3}(\%)$ & 14,3 & 18,9 & 11,9 & 24,7 & 10,7 & 9,9 \\
\hline
\end{tabular}

(1) Somatório.

Médias seguidas de letras distintas, na coluna, dentro de cada fator, diferem estatisticamente pelo teste de $\mathrm{DMS}(\mathrm{P}=0,05)$. $\mathrm{CV}$ : coeficiente de variação das parcelas; $\mathrm{CV}_{2}$ : coeficiente de variação das subparcelas; $\mathrm{CV}_{3}$ : coeficiente de variação das subsubparcelas. 

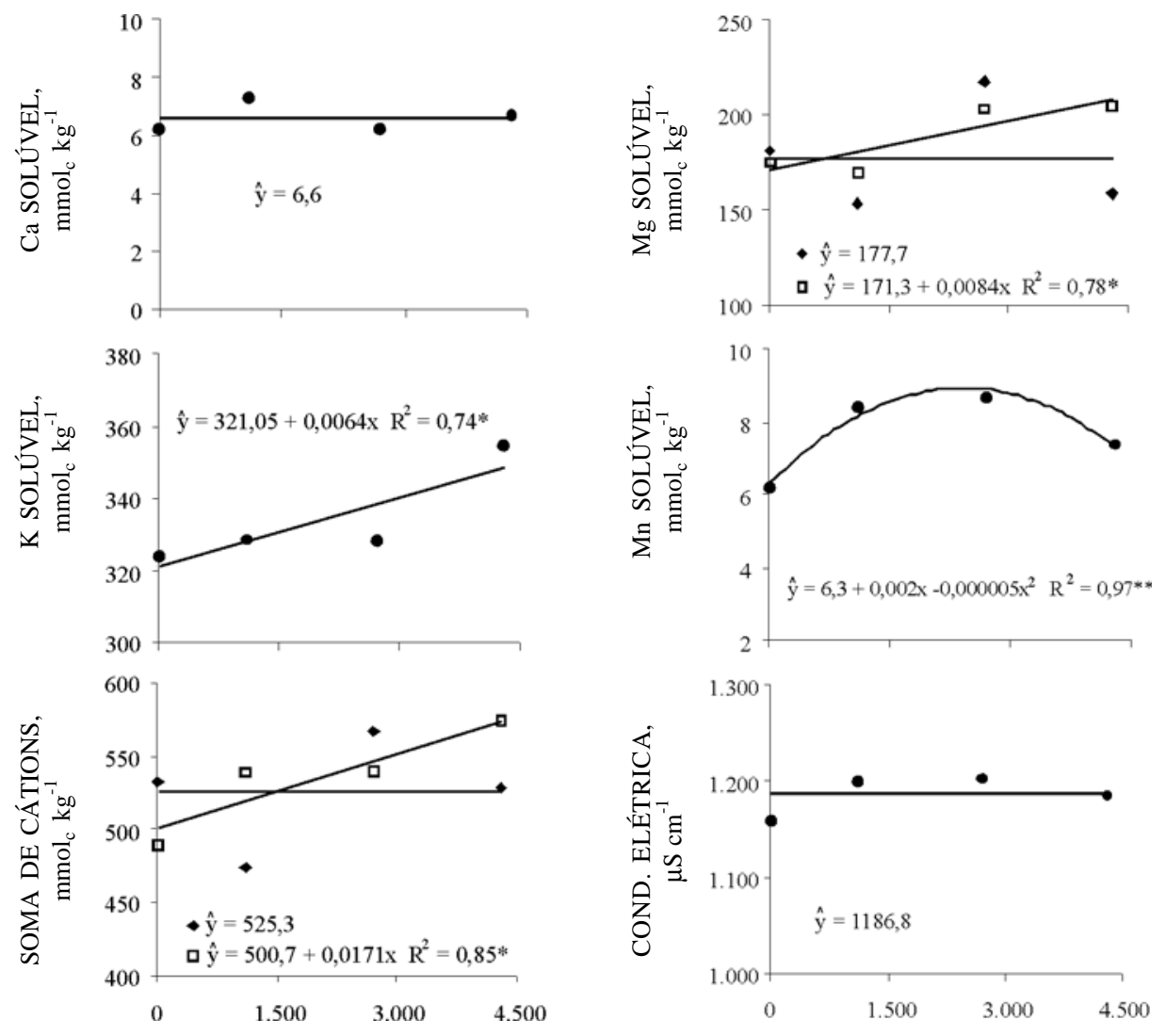

CALCÁRIO, $\mathrm{kg} \mathrm{ha}^{-1}$

Figura 1. Teores de cátions solúveis nos resíduos vegetais em plantas de cultivares de arroz na época do florescimento e condutividade elétrica do extrato, considerando a aplicação de calcário em superfície. Média de dois cultivares. (๑) média dos tratamentos com e sem aplicação de gesso, ( $\diamond)$ sem gesso e ( $\square$ ) com gesso. * $\mathrm{e}$ ** são significativos a 5 e $1 \%$ pelo teste $t$.

No caso da cultura da aveia-preta, cultivada no inverno de 2003, a aplicação de gesso promoveu aumento nos teores de Ca e redução nos teores de $\mathrm{Mg}$ solúveis (Quadro 2). Houve interação significativa entre calagem e gessagem para os teores de Ca solúvel; a aplicação de calcário promoveu aumento nos teores deste elemento apenas na ausência de gesso. Entretanto, na presença de gesso foram observados maiores teores de Ca solúvel, independentemente da dose de calcário utilizada (Quadro 2 e Figura 2).

De maneira geral, a aplicação de calcário proporcionou aumento na soma de cátions solúveis nos extratos do resíduo da aveia-preta, principalmente por aumentar o teor de $\mathrm{Ca}$ e $\mathrm{Mg}$ solúveis no resíduo (Figura 2). No entanto, não se observou correspondente aumento da condutividade elétrica do extrato, o que pode indicar a necessidade de quantificação de outros cátions solúveis $\left(\mathrm{NH}_{4}{ }^{+}, \mathrm{Fe}^{2+}\right.$ etc.). Contudo, como a soma de cátions solúveis pode indicar a quantidade de $\mathrm{H}^{+}$e $\mathrm{Al}^{3+}$ que pode ser neutralizada pelos resíduos vegetais (Miyazawa et al., 2000), a calagem e a gessagem superficiais, além de agirem diretamente na correção da acidez do solo, podem melhorar a capacidade dos resíduos das plantas cultivadas na área em mobilizar Ca e imobilizar $\mathrm{Al}$ da solução do solo.

A aplicação de gesso proporcionou redução no teor de Mg solúvel na parte aérea do feijoeiro, na época do florescimento (Quadro 3), como também foi observado para a aveia-preta em 2003 (Quadro 2). Esse efeito temporal possivelmente está associado à elevada solubilidade do gesso; no entanto, vale destacar que ele não foi observado para o K. Diversos trabalhos têm relatado menor absorção de $\mathrm{Mg}$ pela planta em decorrência da aplicação de gesso em superfície (Oliveira \& Pavan, 1996; Caires et al., 1998, 1999, 2003). Esses autores atribuíram a menor absorção de $\mathrm{Mg}$ à maior lixiviação do elemento provocada pela aplicação de gesso, devido à formação do par iônico neutro $\left(\mathrm{MgSO}_{4}{ }^{\circ}\right)$.

Assim como na cultura do arroz, também para o feijoeiro constatou-se diferença entre os cultivares quanto à concentração de cátions solúveis na parte aérea (Quadro 3). O cultivar Carioca apresentou maior soma de cátions solúveis, com destaque para o Ca e o Mn. No entanto, a variação nos teores de cátions solúveis não foi suficiente para promover alteração na condutividade elétrica do extrato. 
Quadro 2. Teores de cátions solúveis nos resíduos vegetais de aveia-preta (2003) na época do florescimento e condutividade elétrica do extrato, considerando a aplicação superficial de gesso

\begin{tabular}{|c|c|c|c|c|c|c|}
\hline \multirow{2}{*}{ Gesso } & \multicolumn{5}{|c|}{ Cátion solúvel } & \multirow{2}{*}{ Condutividade elétrica } \\
\hline & $\mathbf{C a}^{2+}$ & $\mathbf{M g}^{2+}$ & $\mathbf{K}^{+}$ & $\mathrm{Mn}^{2+}$ & $\Sigma^{(1)}$ & \\
\hline & \multicolumn{5}{|c|}{$-\mathrm{mmol}_{\mathrm{c}} \mathrm{kg}^{-1}$} & $\mu \mathrm{S} \mathrm{cm}^{-1}$ \\
\hline $\begin{array}{l}\text { Sem } \\
\text { Com }\end{array}$ & $\begin{array}{l}76,8 \mathrm{~b} \\
99,2 \mathrm{a}\end{array}$ & $\begin{array}{l}126,7 \mathrm{a} \\
110,8 \mathrm{~b}\end{array}$ & $\begin{array}{l}398,0 \\
401,5\end{array}$ & $\begin{array}{l}5,0 \\
5,0\end{array}$ & $\begin{array}{l}606,5 \\
616,5\end{array}$ & $\begin{array}{l}1.426 \\
1.479\end{array}$ \\
\hline Média & 88,0 & 118,8 & 399,9 & 5,0 & 611,9 & 1.453 \\
\hline $\begin{array}{l}\mathrm{CV}_{1}(\%) \\
\mathrm{CV}_{2}(\%)\end{array}$ & $\begin{array}{l}16,2 \\
13,3\end{array}$ & $\begin{array}{l}13,5 \\
13,7\end{array}$ & $\begin{array}{l}16,7 \\
14,2\end{array}$ & $\begin{array}{l}26,4 \\
10,9\end{array}$ & $\begin{array}{r}12,1 \\
9,7\end{array}$ & $\begin{array}{r}10,5 \\
9,8\end{array}$ \\
\hline
\end{tabular}

\section{(1) Somatório.}

Médias seguidas de letras distintas, na coluna, diferem estatisticamente pelo teste de DMS $(\mathrm{P}=0,05)$. CV $\mathrm{C}_{1}$ coeficiente de variação das parcelas; $\mathrm{CV}_{2}$ : coeficiente de variação das subparcelas.
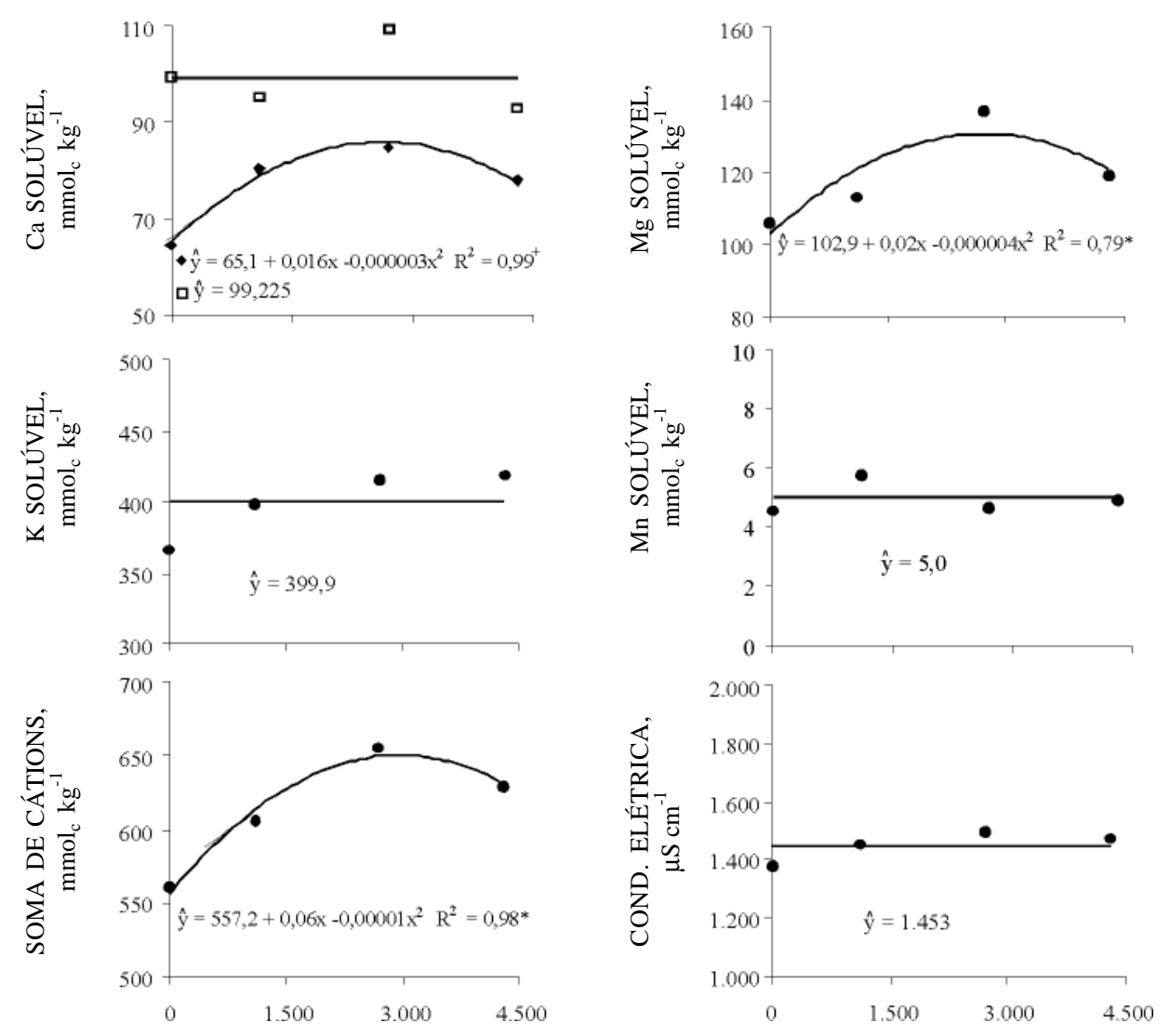

CALCÁRIO, $\mathrm{kg} \mathrm{ha}^{-1}$

Figura 2. Teores de cátions solúveis nos resíduos vegetais em plantas de aveia-preta (2003) na época do florescimento e condutividade elétrica do extrato, considerando a aplicação de calcário em superfície. (๑) média dos tratamentos com e sem aplicação de gesso, ( $\diamond)$ sem gesso e (口) $\operatorname{com}$ gesso. ${ }^{+}, *$ e ** significativos a 10, 5 e $1 \%$ pelo teste t.

A calagem promoveu redução no teor de $\mathrm{Mg}$ solúvel na parte aérea do feijoeiro (Figura 3). Os teores solúveis de Ca e Mg no feijoeiro são muito superiores aos verificados no arroz e na aveia-preta, e os teores de K são ligeiramente superiores; nessa situação de alta demanda por $\mathrm{Ca}$ e $\mathrm{K}$, a absorção de $\mathrm{Mg}$ pode ter sido limitada pelo aumento da atividade do $\mathrm{K}$ na solução, deslocado do complexo de troca pelos cátions divalentes. Crusciol et al. (2003) também observaram redução no teor de Mg nas folhas do amendoim em decorrência da aplicação de doses de calcário dolomítico no sulco de semeadura. 
Quadro 3. Teores de cátions solúveis nos resíduos vegetais de cultivares de feijão na época do florescimento e condutividade elétrica do extrato, considerando a aplicação superficial de gesso

\begin{tabular}{|c|c|c|c|c|c|c|}
\hline \multirow{2}{*}{ Tratamento } & \multicolumn{5}{|c|}{ Cátion solúvel } & \multirow{2}{*}{ Condutividade elétrica } \\
\hline & $\mathbf{C a}^{2+}$ & $\mathbf{M g}^{2+}$ & $\mathbf{K}^{+}$ & $\mathrm{Mn}^{2+}$ & $\Sigma^{(1)}$ & \\
\hline Gesso & \multicolumn{5}{|c|}{$-\mathrm{mmol}_{\mathrm{c}} \mathrm{kg}^{-1}$} & $\mu \mathrm{S} \mathrm{cm}^{-1}$ \\
\hline Sem & 431,3 & $506,9 \mathrm{a}$ & 411,5 & 2,8 & $1.352,5$ & 1.653 \\
\hline Com & 474,5 & $431,4 \mathrm{~b}$ & 401,9 & 2,9 & $1.310,7$ & 1.618 \\
\hline \multicolumn{7}{|l|}{ Cultivar } \\
\hline Carioca & $498,3 \mathrm{a}$ & 468,6 & 412,4 & $3,2 \mathrm{a}$ & $1.382,5 \mathrm{a}$ & 1.626 \\
\hline Pérola & $407,4 \mathrm{~b}$ & 469,7 & 400,9 & $2,5 \mathrm{~b}$ & $1.280,5 \mathrm{~b}$ & 1.644 \\
\hline Média & 452,8 & 469,2 & 406,7 & 2,8 & $1.331,5$ & 1.635 \\
\hline $\mathrm{CV}_{1}(\%)$ & 25,6 & 16,6 & 19,7 & 45,3 & 16,0 & 11,1 \\
\hline $\mathrm{CV}_{2}(\%)$ & 20,3 & 17,4 & 5,9 & 28,5 & 9,5 & 9,0 \\
\hline $\mathrm{CV}_{3}(\%)$ & 22,9 & 12,3 & 12,1 & 34,6 & 9,8 & 8,7 \\
\hline
\end{tabular}

(1) Somatório.

Médias seguidas de letras distintas, na coluna, dentro de cada fator (gesso e cultivar), diferem estatisticamente pelo teste de DMS $(\mathrm{P}=0,05) . \mathrm{CV}_{1}$ : coeficiente de variação das parcelas; $\mathrm{CV}_{2}$ : coeficiente de variação das subparcelas; $\mathrm{CV}_{3}$ : coeficiente de variação das subsubparcelas.
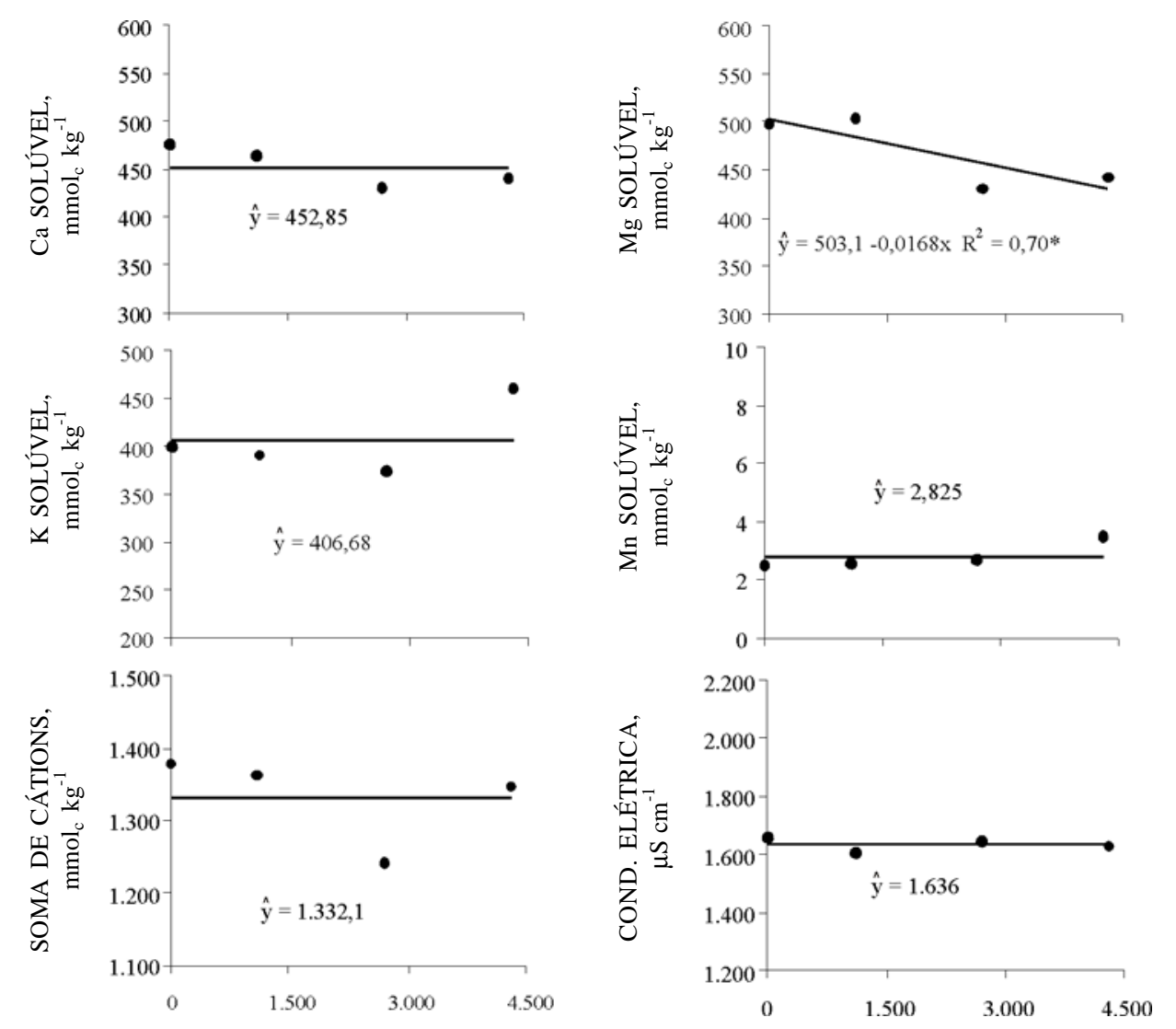

CALCÁRIO, $\mathrm{kg} \mathrm{ha}^{-1}$

Figura 3. Teores de cátions solúveis nos resíduos vegetais em plantas de cultivares de feijão na época do florescimento e condutividade elétrica do extrato, considerando a aplicação de calcário em superfície. Média de dois cultivares. * $\mathrm{e} * *$ significativos a 5 e $1 \%$ pelo teste $t$.

No segundo ano de cultivo da aveia-preta, os cátions solúveis nos extratos da parte aérea não tiveram influência dos tratamentos (Quadro 4).
De modo geral, os resíduos da cultura do arroz mostraram baixo teor de Ca solúvel; o feijoeiro se destacou, apresentando cerca de 70 vezes mais $\mathrm{Ca}$ 
solúvel no resíduo vegetal do que o arroz (Quadro 5). A aveia-preta apresentou teor de $\mathrm{Ca}$ solúvel intermediário, porém muito superior ao da cultura do arroz. Meda et al. (2001) verificaram maior teor de Ca solúvel em resíduos de aveia-preta (no florescimento) em comparação com a palha de arroz (após a colheita). Os autores atribuíram o menor teor - principalmente de Ca solúvel - ao avançado estádio fenológico da planta, já que plantas na fase de pleno crescimento vegetativo apresentam maiores teores de cátions solúveis (Franchini et al., 2003). No entanto, vale ressaltar que no presente trabalho as amostragens de plantas para determinação dos cátions solúveis foram realizadas no florescimento, indicando que a cultura do arroz apresenta baixo teor de Ca solúvel mesmo em época na qual a atividade metabólica é alta, conforme Miyazawa et al. (1993) e Meda et al. (2001) que haviam observado em resíduos de outras gramíneas, notadamente o centeio e o milheto.

Há grande variabilidade entre as espécies quanto à solubilidade dos cátions, sobretudo do Ca (Quadro 5), como já havia sido observado por Franchini et al. (2001) e Meda et al. (2001, 2002). Resíduos vegetais com maiores teores de Ca solúvel são mais eficientes em imobilizar Al (Franchini, 2004). Assim, é de se esperar maior efeito dos resíduos vegetais do feijão e, principalmente, da aveia-preta na redução da atividade do $\mathrm{Al}^{3+}$, já que esta última, de modo geral, produziu maior quantidade de resíduos por área.

Quanto aos teores de Mg solúvel, verificou-se no resíduo do feijoeiro valor maior que o das demais culturas, semelhante ao observado para o $\mathrm{Ca}$ (Quadro 5). Os teores de Mn solúvel foram baixos nos resíduos de todas as culturas, o que está relacionado com o baixo teor desse nutriente que as plantas apresentam.

Para Franchini (2004), os resíduos vegetais que apresentam maior capacidade para mobilizar Ca são aqueles com alto teor de $\mathrm{K}$ no tecido, destacando-se a aveia-preta e o nabo forrageiro. No presente estudo, a cultura da aveia-preta, no segundo ano de cultivo, apresentou maior teor de K solúvel, assim como de

Quadro 4. Teores de cátions solúveis nos resíduos vegetais de aveia-preta (2004) na época do florescimento e condutividade elétrica do extrato, considerando a aplicação superficial de gesso

\begin{tabular}{|c|c|c|c|c|c|c|}
\hline \multirow{2}{*}{ Tratamento } & \multicolumn{5}{|c|}{ Cátion solúvel } & \multirow{2}{*}{ Condutividade elétrica } \\
\hline & $\mathbf{C a}^{2+}$ & $\mathrm{Mg}^{2+}$ & $\mathbf{K}^{+}$ & $\mathrm{Mn}^{2+}$ & $\Sigma^{(1)}$ & \\
\hline Gesso & \multicolumn{5}{|c|}{$\mathrm{mmol}_{\mathrm{c}} \mathrm{kg}^{-1}$} & $\mu \mathrm{S} \mathrm{cm}^{-1}$ \\
\hline $\begin{array}{l}\text { Sem } \\
\text { Com }\end{array}$ & $\begin{array}{l}139,4 \\
129,6\end{array}$ & $\begin{array}{l}183,5 \\
168,0\end{array}$ & $\begin{array}{l}527,1 \\
526,1\end{array}$ & $\begin{array}{l}6,2 \\
6,4\end{array}$ & $\begin{array}{l}856,2 \\
830,1\end{array}$ & $\begin{array}{l}1.828 \\
1.839\end{array}$ \\
\hline Média & 134,5 & 175,8 & 526,6 & 6,3 & 843,2 & 1.834 \\
\hline $\mathrm{CV}_{1}(\%)$ & 22,9 & 17,2 & 18,8 & 31,8 & 15,9 & 11,3 \\
\hline $\mathrm{CV}_{2}(\%)$ & 14,5 & 18,3 & 14,1 & 29,9 & 9,8 & 8,7 \\
\hline
\end{tabular}

(1) Somatório.

Médias seguidas de letras distintas, na coluna, diferem estatisticamente pelo teste de $\mathrm{DMS}(\mathrm{P}=0,05)$. $\mathrm{CV}_{1}$ : coeficiente de variação das parcelas; $\mathrm{CV}_{2}$ : coeficiente de variação das subparcelas.

Quadro 5. Teores de cátions solúveis nos resíduos vegetais e produção de matéria seca da parte aérea das culturas de arroz, aveia-preta e feijão na época do florescimento e condutividade elétrica do extrato

\begin{tabular}{|c|c|c|c|c|c|c|c|}
\hline \multirow{2}{*}{ Cultura } & \multicolumn{5}{|c|}{ Cátion solúvel } & \multirow{2}{*}{ Matéria seca } & \multirow{2}{*}{ Condutividade elétrica } \\
\hline & $\mathrm{Ca}^{2+}$ & $\mathbf{M g}^{2+}$ & $\mathbf{K}^{+}$ & $\mathbf{M n}^{2+}$ & $\sum(1)$ & & \\
\hline & \multicolumn{5}{|c|}{$-\mathrm{mmol}_{\mathrm{c}} \mathrm{kg}^{-1}$} & $\mathrm{~kg} \mathrm{ha}^{-1}$ & $\mu \mathrm{S} \mathrm{cm}-1$ \\
\hline Arroz $(2002 / 03)$ & 6,6 & 183,0 & 333,8 & 7,7 & 531,1 & 6.082 & 1.187 \\
\hline Aveia-preta (2003) & 88,0 & 118,8 & 399,9 & 5,0 & 611,9 & 4.879 & 1.453 \\
\hline Feijão (2003/04) & 452,8 & 469,2 & 406,7 & 2,8 & $1.331,5$ & 2.058 & 1.635 \\
\hline Aveia-preta (2004) & 134,5 & 175,8 & 526,6 & 6,3 & 843,2 & 6.258 & 1.833 \\
\hline
\end{tabular}

\footnotetext{
(1) Somatório.
}

Médias dos tratamentos estudados em cada cultura. 
$\mathrm{Ca}, \mathrm{Mg}$, soma de cátions e condutividade elétrica (Quadro 5). No entanto, no primeiro ano de cultivo, o teor de K solúvel na aveia-preta foi semelhante ao observado nos resíduos do arroz e do feijão. O maior teor de cátions no segundo ano de cultivo da aveiapreta pode estar relacionado com a maior disponibilidade hídrica, que, provavelmente, possibilitou maior absorção desses elementos. Outro aspecto que deve ser ressaltado é que em 2003 a aveiapreta foi cultivada em sucessão à cultura do arroz e, em 2004, à do feijão, que apresentou maior teor de cátions solúveis na parte aérea, em relação ao arroz. Além disso, o feijoeiro é uma leguminosa que apresenta menor relação $\mathrm{C} / \mathrm{N}$ do que gramíneas, disponibilizando, dessa forma, mais rapidamente os nutrientes contidos em seus restos culturais para a cultura subseqüente.

Com exceção do feijoeiro, que apresentou maiores teores de $\mathrm{Mg}$ e Ca do que de $\mathrm{K}$ no extrato, as demais culturas apresentaram a seguinte ordem decrescente de cátions solúveis nos extratos dos resíduos vegetais: $\mathrm{K}>\mathrm{Mg}>\mathrm{Ca}>\mathrm{Mn}>\mathrm{Na}$, semelhante ao relatado por Meda et al. (2002) para extratos de plantas invasoras. Essa ordem de solubilidade pode ser explicada pela função e mobilidade que os elementos apresentam na planta (Malavolta et al., 1997). O K é altamente móvel no floema, formando ligações com complexos orgânicos de fácil reversibilidade (Rosolem et al., 2003); praticamente todo o $\mathrm{K}$ no tecido vegetal pode ser solubilizado no extrato (Meda et al., 2002). Assim como o $\mathrm{K}$, o $\mathrm{Mg}$ apresenta mobilidade no floema, mas pode estar associado a ânions pouco solúveis em água. Já o Ca exerce papel fundamental na estruturação de membranas e paredes celulares, estando fortemente ligado a esses componentes, de baixa solubilidade em água, sendo, portanto, pouco móvel no floema (Meda et al., 2002).

Quanto à soma de cátions solúveis, nota-se que a cultura do feijão apresentou os maiores valores, seguida da de aveia-preta. O resultado que fica mais evidente é o baixo teor de Ca solúvel nos resíduos vegetais das plantas de arroz, indicando que mesmo no florescimento os resíduos desta cultura têm baixo potencial para neutralizar a acidez do solo, conforme já havia sido relatado por Miyazawa et al. (2000) e Meda et al. (2001). A condutividade elétrica dos extratos vegetais indica a concentração dos íons dissolvidos na solução, onde os valores podem-se correlacionar positivamente com a determinação da soma de cátions (Miyazawa et al., 2000). Da mesma forma, Franchini et al. (1999a) constataram que as variações na condutividade elétrica foram relacionadas com os teores solúveis de bases nos resíduos vegetais. No entanto, verifica-se que, mesmo tendo apresentado maior somatória de cátions solúveis, influenciada, principalmente, pelo maior teor de $\mathrm{Ca}$, o extrato vegetal do feijoeiro mostrou condutividade elétrica inferior à da aveia-preta, no segundo ano de cultivo. O extrato da cultura do arroz apresentou menor condutividade elétrica, decorrente do menor teor de cátions dissolvidos na solução.

\section{CONCLUSÕES}

1. Os teores de cátions solúveis na parte aérea das culturas de arroz, feijão e aveia-preta foram alterados pelas aplicações de calcário e gesso em superfície.

2. A gessagem em superfície aumentou os teores solúveis de Ca e reduziu o de $\mathrm{Mg}$ na parte aérea das culturas, principalmente nas primeiras safras após a aplicação.

3. A calagem aumentou os teores de cátions solúveis na parte aérea das culturas.

4. As culturas do feijão e da aveia-preta apresentaram maiores teores de cátions solúveis nos resíduos da parte aérea, avaliados no florescimento.

\section{AGRADECIMENTO}

À Fapesp, pelo apoio financeiro.

\section{LITERATURA CITADA}

AMARAL, A.S.; ANGHINONI, I. \& DESCHAMPS, F.C. Resíduos de plantas de cobertura e do calcário aplicado na superfície do solo. R. Bras. Ci. Solo, 28:115-123, 2004.

CAIRES, E.F. Manejo da fertilidade do solo no sistema plantio direto: Experiências no Estado do Paraná. In: REUNIÃO BRASILEIRA DE FERTILIDADE DO SOLO E NUTRIÇÃO DE PLANTAS, 25., Santa Maria, 2000. Anais. Santa Maria, Sociedade Brasileira de Ciência do Solo, 2000. 28p. CD-ROM.

CAIRES, E.F.; BLUM, J.; BARTH, G.; GARBUIO, F.J. \& KUSMAN, M.T. Alterações químicas do solo e resposta da soja ao calcário e gesso aplicados na implantação do sistema plantio direto. R. Bras. Ci. Solo, 27:275-286, 2003.

CAIRES, E.F.; CHUEIRI, W.A.; MADRUGA, E.F. \& FIGUEIREDO, A. Alterações de características químicas do solo e resposta da soja ao calcário e gesso aplicados na superfície em sistema de cultivo sem preparo de solo. R. Bras. Ci. Solo, 22:27-34, 1998.

CAIRES, E.F.; FONSECA, A.F.; MENDES, J.; CHUEIRI, W. \& MADRUGA, E.F. Produção de milho, trigo e soja em função das alterações das características químicas do solo pela aplicação de calcário e gesso na superfície, em sistema plantio direto. R. Bras. Ci. Solo, 23:315-327, 1999.

CASSIOLATO, M.E.; MEDA, A.R.; PAVAN, M.A.; MIYAZAWA, M. \& OLIVEIRA, J.C. Evaluation of oat extracts on the efficiency of lime in soil. Braz. Arch. Biol. Technol., 43:533$536,2000$.

CASSIOLATO, M.E.; MIYAZAWA, M.; MEDA, A.R. \& PAVAN, M.A. A laboratory method to estimate the efficiency of plant extract to neutralize soil acidity. Braz. Arch. Biol. Technol., 45:183-187, 2002. 
CRUSCIOL, C.A.C.; LAZARINI, E. \& SORATTO, R.P. Efeito da aplicação de calcário no sulco de semeadura sobre a nutrição e produtividade de amendoim semeado em diferentes épocas no cultivo da seca. Científica, 31:201209, 2003.

EMPRESA BRASILEIRA DE PESQUISA AGROPECUÁRIA . EMBRAPA. Sistema Brasileiro de Classificação dos Solos. Rio de Janeiro, 1999. 412p.

FRANCHINI, J.C. Influência de resíduos vegetais na toxidez de $\mathrm{Al}$ e na mobilidade de íons no solo. In: REUNIÃO BRASILEIRA DE FERTILIDADE DO SOLO E NUTRIÇÃO DE PLANTAS, 26., Lages, 2004. Anais. Lages, SBCS/UDESC, 2004. CD-ROM.

FRANCHINI, J.C.; HOFFMANN-CAMPO, C.B.; TORRES, E.; MIYAZAWA, M. \& PAVAN, M.A. Organic composition of green manures during growth and its effect on cation mobilization in an acid Oxisol. Comm. Soil Sci. Plant Anal., 34:2045-2058, 2003.

FRANCHINI, J.C.; MALAVOLTA, E.; MIYAZAWA, M. \& PAVAN, M.A. Alterações químicas em solos ácidos após a aplicação de resíduos vegetais. R. Bras. Ci. Solo, 23:533542, 1999a.

FRANCHINI, J.C.; MEDA, A.R.; CASSIOLATO, M.E.; MIYAZAWA, M. \& PAVAN, M.A. Potencial de extratos de resíduos vegetais na mobilização do calcário no solo por métodos biológicos. Sci. Agric., 58:357-360, 2001.

FRANCHINI, J.C.; MIYAZAWA, M.; PAVAN, M.A. \& MALAVOLTA, E. Dinâmica de íons em solo ácido lixiviado com extratos de resíduos vegetais de adubos verdes e soluções puras de ácidos orgânicos. Pesq. Agropec. Bras., 34:2267-2276, 1999b.

MALAVOLTA, E.; VITTI, G.C. \& OLIVEIRA, S.A. Avaliação do estado nutricional de plantas: Princípios e aplicações. 2.ed. Piracicaba, Potafos, 1997. 319p.
MEDA, A.R.; CASSIOLATO, M.E.; PAVAN, M.A. \& MIYAZAWA, M. Alleviating soil acidity through plant organic compounds. Braz. Arch. Biol. Technol., 44:185$189,2001$.

MEDA, A.R.; PAVAN, M.A.; MIYAZAWA, M. \& CASSIOLATO, M.E. Plantas invasoras para melhorar a eficiência da calagem na correção da acidez subsuperficial do solo. R. Bras. Ci. Solo, 26:647-654, 2002.

MIYAZAWA, M.; PAVAN, M.A. \& CALEGARI, A. Efeito de material vegetal na acidez do solo. R. Bras. Ci. Solo, 17:411416, 1993 .

MIYAZAWA, M.; PAVAN, M.A. \& FRANCHINI, J.C. Evaluation of plant residues on the mobility os surface applied lime. Braz. Arch. Biol. Technol., 45:251-256, 2002.

MIYAZAWA, M.; PAVAN, M.A. \& FRANCHINI, J.C. Neutralização da acidez do perfil do solo por resíduos vegetais. Inf. Agron., 92:1-8, 2000.

OLIVEIRA, E.L. \& PAVAN, M.A. Control of soil acidity in notillage system for soybean production. Soil Till. Res., 38:4757, 1996.

OLSEN, S.R. \& WATANABE, F.S. Interaction of added gypsum in alkaline soils with uptke of iron, molybdenum, manganese and zinc by sorghum. Soil Sci. Soc. Am. J., 43:125-130, 1979.

PIERRE, W.H. \& BANWART, W.L. Excess-base and excessbase/nitrogen ratio of various crop species and parts of plant. Agron. J., 65:91-96, 1973.

RAIJ, B. van; ANDRADE, J.C.; CANTARELLA, H. \& QUAGGIO, J.A. Análise química para avaliação da fertilidade de solos tropicais. Campinas, Instituto Agronômico, 2001. 284p.

ROSOLEM, C.A.; CALONEGO, J.C. \& FOLONI, J.S.S. Lixiviação de potássio da palha de espécies de cobertura do solo de acordo com a quantidade de chuva aplicada. R. Bras. Ci. Solo, 27:355-362, 2003. 